\title{
STUDIES ON NORTH AMERICAN CARBONIFEROUS INSECTS. 2. THE GENUS BRODIOPTERA, FROM THE MARITIME PROVINCES, CANADA*
}

\author{
By F. M. Carpenter \\ Harvard University
}

Although few in number, the insects which have been found in the Upper Carboniferous strata of the Maritime Provinces of Canada are of exceptional interest. They occur in rocks which are well down in the Westphalian stage (Zone A) and are therefore only a little younger than the oldest insects known (Namurian). In 1957, Dr. M. J. Copeland of the Canada Department of Mines and Technical Surveys published an account of the arthropod fauna of the Upper Carboniferous rocks of these provinces and included descriptions of two species of the genus Brodioptera, which he placed in the Order Megasecoptera. Since Dr. Copeland's descriptions and illustrations are inadequate for our present needs of interpreting the relationships of these insects, I have found it necessary to make a study of this material. I am indebted to Dr. Copeland for arranging to have the type specimens loaned to me for this purpose.

One of the species which Copeland placed in Brodioptera is a member of the Order Megascoptera, as thought by him, although its affinities within the group are different from those which he assumed; the other species described in Brodioptera is not a megasecopteron at all but very clearly a member of the Order Palaeodictyoptera.

\section{Order Megasecoptera \\ Family Brodiopteridae, new family}

Anterior margin of wing very nearly straight proximally; hind margin apparently nearly straight or only slightly curved; the wing was almost certainly not petiolate, although the absence of the basal part of the hind margin permits the possibility of a slight narrowing in that region. Sc terminating on $\mathrm{C}, \mathrm{Rl}$ straight at the base of the wing, not arched proximally; MA free from $\mathrm{Rs}$, and $\mathrm{Cu}$ and $\mathrm{CuA}$ free from MP; one anal vein. Cross veins few and widely scattered.

This family is probably more closely related to the Sphecopteridae and the Corydaloididae than to any other known families of the order.

\footnotetext{
*This research has been aided by a grant (NSF-G14099) from the National Science Foundation. The previous part of this series was published in Psyche, $67: 98-110,1961$.
} 
It is far removed from the family Brodiidae, within which it was placed by Copeland; it lacks the extreme petiolation characteristic of the Brodiidae, and more significantly, lacks the strikingly serrate costal margin, which is the outstanding feature of the brodiids. In the sphecopterids the subcosta terminates on the radius, the radial sector (at least in the fore wing) is anastomosed for a short distance with MA, and the cross veins are very regularly arranged, forming definite rows. In the corydaloidids the subcosta terminates in the costal area without definitely ending on either the costa or $\mathrm{Rl}$; and there is a brief anastomosis of MA with Rs and of $\mathrm{CuA}$ with $\mathrm{M}$.

\section{Brodioptera Copeland, 1957}

Brodioptera Copeland 1957, Geological Survey of Canada, Mem. 286:53.

Wing venation: Sc terminating about two-thirds of the wing length from the base; Rs with several branches, MA, MP (apparently), CuA and CuP unbranched.

Type species: Brodioptera cumberlandensis Copeland.

\section{Brodioptera cumberlandensis Copeland, 1957} Figure I

Brodioptera cumberlandensis Copeland, 1957, Geol. Surv. Canada, Mem. 286: 53.

Length of wing, $17 \mathrm{~mm}$; maximum width, $4.5 \mathrm{~mm} .^{1}$ Apex of wing rounded; Rs branched to form $\mathrm{R}_{2} \mathrm{a}, \mathrm{R} 2 \mathrm{~b}, \mathrm{R}_{3}, \mathrm{R}_{4}+5$; MA arising slightly distad of the origin of Rs; $\mathrm{CuA}$ arising much nearer the base of the wing. The arrangement of cross veins is shown in figure $\mathrm{I}$.

Type: no. I0390 (obverse and reverse), Geological Survey of Canada. This consists of a fairly well-preserved wing, lacking only the very base and a few small areas near the middle of the wing. Whether the wing is a fore or hind wing cannot be determined. The convexities and concavities of the veins are clearly indicated. The specimen was collected by Henry M. Ami, in 1899, in deposits at West Bay, Plarrsboro, Cumberland County, Nova Scotia. The deposit is stated by Dr. Copeland to belong to the Riversdale group and more specifically by Ami as probably of Joggins coalfield, of the Coal Measures.

This specimen is generalized so far as the absence of fusion of main veins is concerned but it is highly specialized in the reduction of branches on all veins accepting Rs, in the close proximity of Sc and $\mathrm{Rl}$ to the costal margin, and in the small number of cross veins. It is surprising to find a megasecopteron as specialized as this in the Rivers-

\footnotetext{
${ }^{1}$ The dimensions are incorrectly indicated on p. 101 of Copeland's paper (1957).
} 
dale group of strata, which is regarded as being about equivalent to Westphalian Zone A, just above the Namurian stage, in which the oldest insects (unquestionable) have been found.

\section{Palaeodictyoptera}

Family Dictyoneuridae Handlirsch ${ }^{2}$

I am placing the species described by Copeland as Brodioptera ami $i^{3}$ in the family Dictyoneuridae, although I have doubts about its actually belonging within the limits of the family. The most distinctive characteristic of the Dictyoneuridae is the presence of an archedictyon over the wing surface. Unfortunately the specimen of amii shows no signs of either cross veins or an archedictyon, probably because of the coarse nature of the matrix in which the fossil is preserved. On the assump-

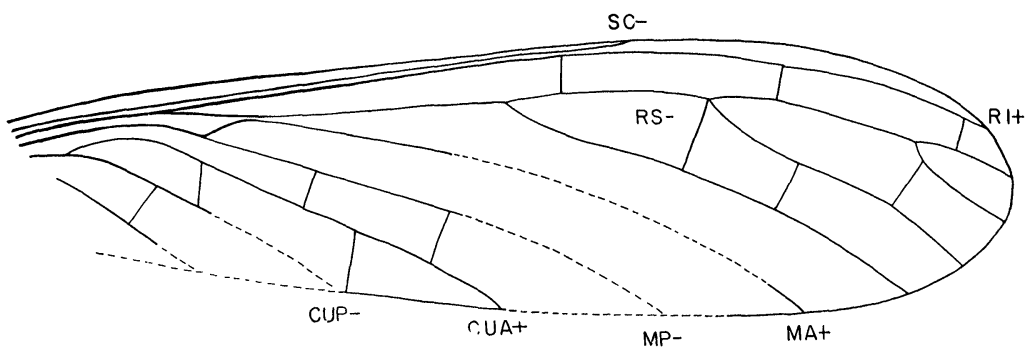

Figure 1. Brodioptera cumberlandensis Copeland. Original drawing, based on holotype. $\mathrm{C}$, costa; Sc, subcosta ; $\mathrm{Rl}$, radius; $\mathrm{RS}$, radial sector; MA, anterior media; MP, posterior media; CUA, anterior cubitus; CUP, posterior cubitus; $1 \mathrm{~A}$, first anal vein.

tions that true cross veins probably would show, if they were present, I am tentatively assigning the species to the Dictyoneuridae. Other characteristics of the family include the subcosta ending on the costal margin, well beyond the middle of the wing; Rl ending nearly at the apex, Rs with at least three branches; MA unbranched and arising as a distinct anterior branch of the media, $\mathrm{CuA}$ typically unbranched (though occasionally with a distal fork) and $\mathrm{CuP}$ with several branches. All of these features occur in the specimen of amii. The one characteristic of amii that has not previously been noted in the Dictyoneuridae is the presence of a definite cross vein joining the anterior media with the radial sector; such a vein, present in amii,

\footnotetext{
${ }^{2}$ The name Stenodictyopteridae Brongniart used by some authors (e.g., Pruvost, 1919; Laurentiaux, 1953) for this family is invalid, since it is not based on a generic name.

${ }^{3}$ The name amiae was used by Dr. Copeland in error. He has informed me (in litt.) that the species was named for Dr. Henry M. Ami, the collector of the fossil, and that the name should accordingly have been amii instead of amiae.
} 
may have been formed by an alignment of the sides of several of the cellules comprising the archedictyon. The wing on which amii is based is quite clearly a hind wing and although this is broader than the hind wings of any known dictyoneurids, the hind wings in several genera are markedly broader in the anal region than the fore wings. The greater differentiation in amii seems to me insufficient to eliminate it from the family on this basis alone. However, a distinct genus seems to be necessary for the fossil, since the genus into which it was placed by Copeland is a megasecopteron.

\section{Schedoneura, new genus}

Main veins of the wing with the general characteristics of the dictyoneurids: Sc and Rs extending almost to the apex, Rs arising just before the middle of the wing, with four branches; MA un-

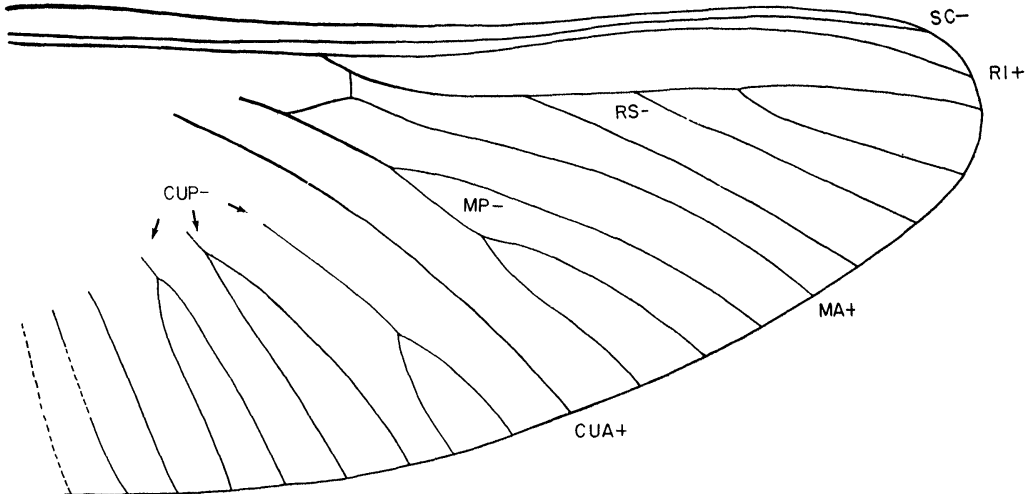

Figure 2. Schedoneura amii (Copeland). Original drawing, based on holotype. Lettering as in figure 1.

branched, joined to the base of $\mathrm{Rs}$ by a distinct cross vein; $\mathrm{CuA}$ unbranched; $\mathrm{CuP}$ very well developed, with six terminal branches; several anal veins.

Type species: Brodioptera amii Copeland

\section{Schedoneura amii (Copeland)}

Figure 2

Brodioptera amii Copeland, 1957, Geol. Surv. Canada, Mem. 286:54, pl. 18, fig. 4-6.

Hind wing: length, $13.5 \mathrm{~mm}$; maximum width, $6.5 \mathrm{~mm} .^{4}$ Branches of Rs about equally spaced, the basal branches arising pectinately, the

\footnotetext{
${ }^{4}$ The dimensions are incorrectly indicated on p. 101 of Copeland's paper (1957).
} 
terminal ones forming a dichotomous fork. MA arises slightly basad of the level of the origin of Rs; MP with three branches; the six terminal branches of $\mathrm{CuP}$ are formed by bifurcation of three main branches, although their origin is not preserved in the fossil. The venational details are shown in text figure 2.

Type no. 10392 (obverse and reverse), Geological Survey of Canada. The specimen was collected by Henry M. Ami, in I899, specifically at Howard's Mills, River Wallace, Cumberland County, Nova Scotia. This is placed by Dr. Copeland in the Riversdale group. The fossil consists of a moderately well-preserved wing, lacking only the base of the anal area and a part extending out towards the center of the wing from the base. The convexities and concavities of the veins are clearly shown but there are no indications of cross veins or of an archedictyon. The distal part of this wing is preserved on the counterpart; the rest of the wing is preserved in one piece.

As indicated above under discussion of the family relationships, the affinites of this fossil are not at all clear. That it is a palaeodictyopteron is obvious; however, the absence of an archedictyon or a cross venational system leaves us somewhat uncertain about its relationships. The main venational pattern, as indicated above, conforms to that of the Dictyoneuridae. 

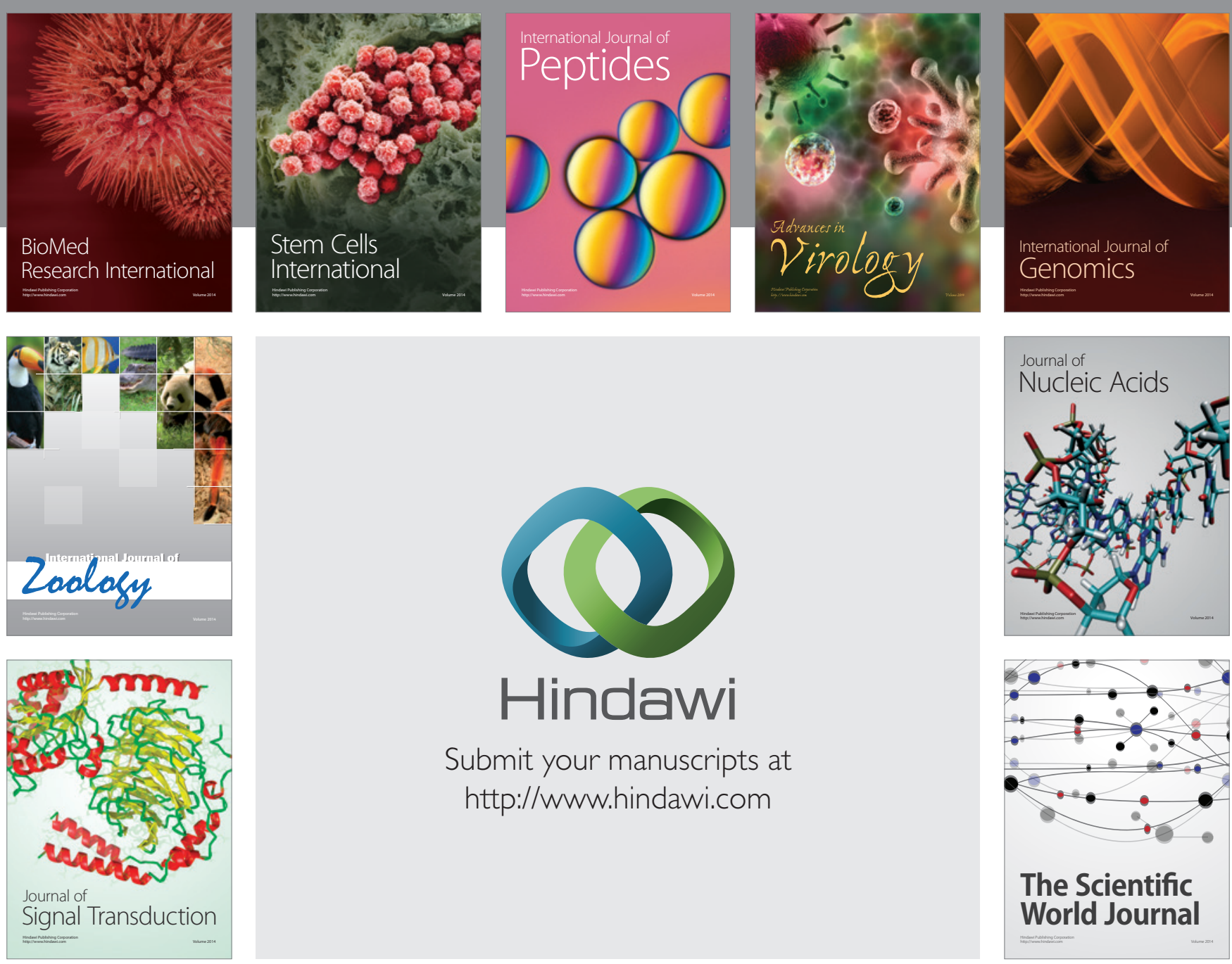

Submit your manuscripts at

http://www.hindawi.com
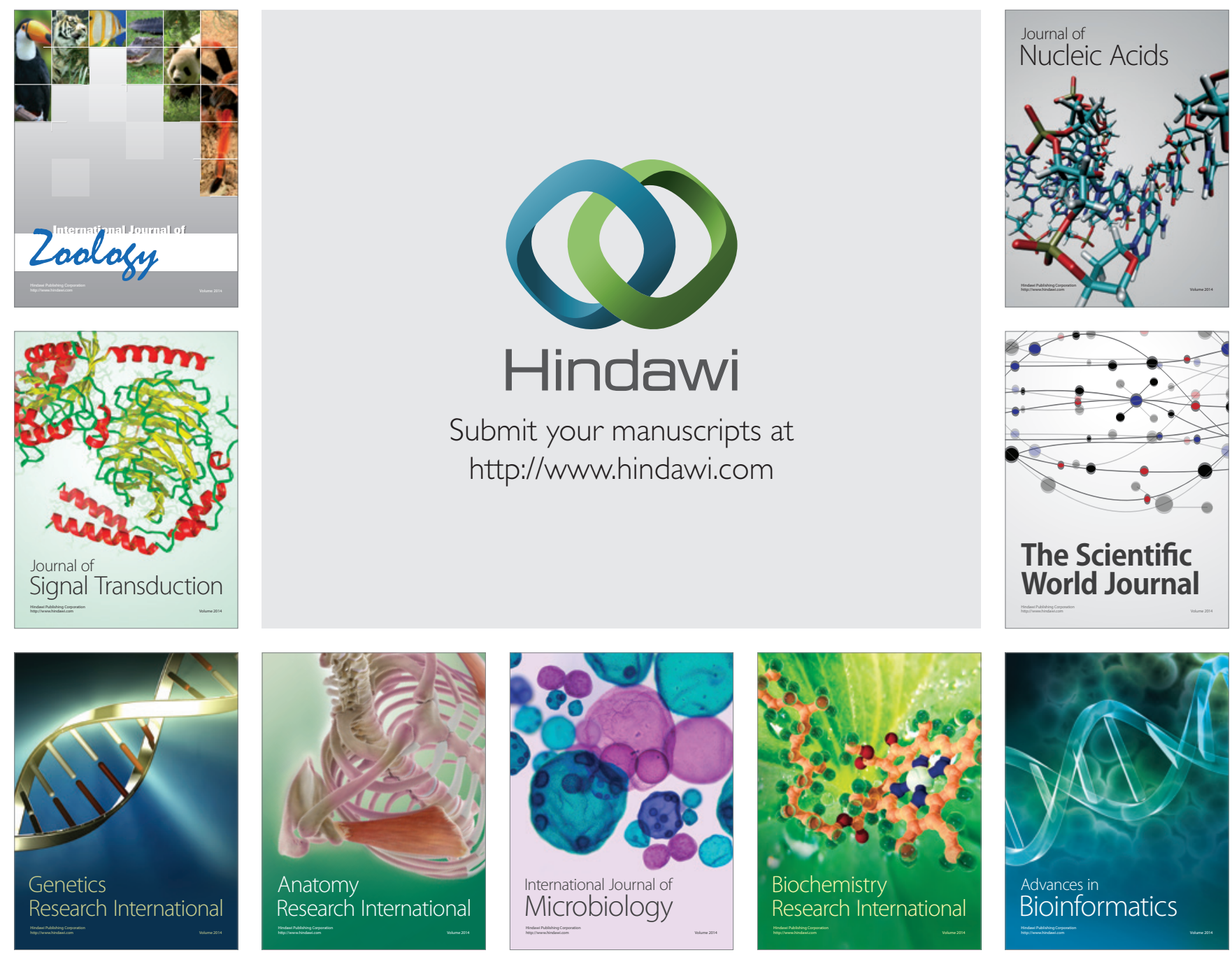

The Scientific World Journal
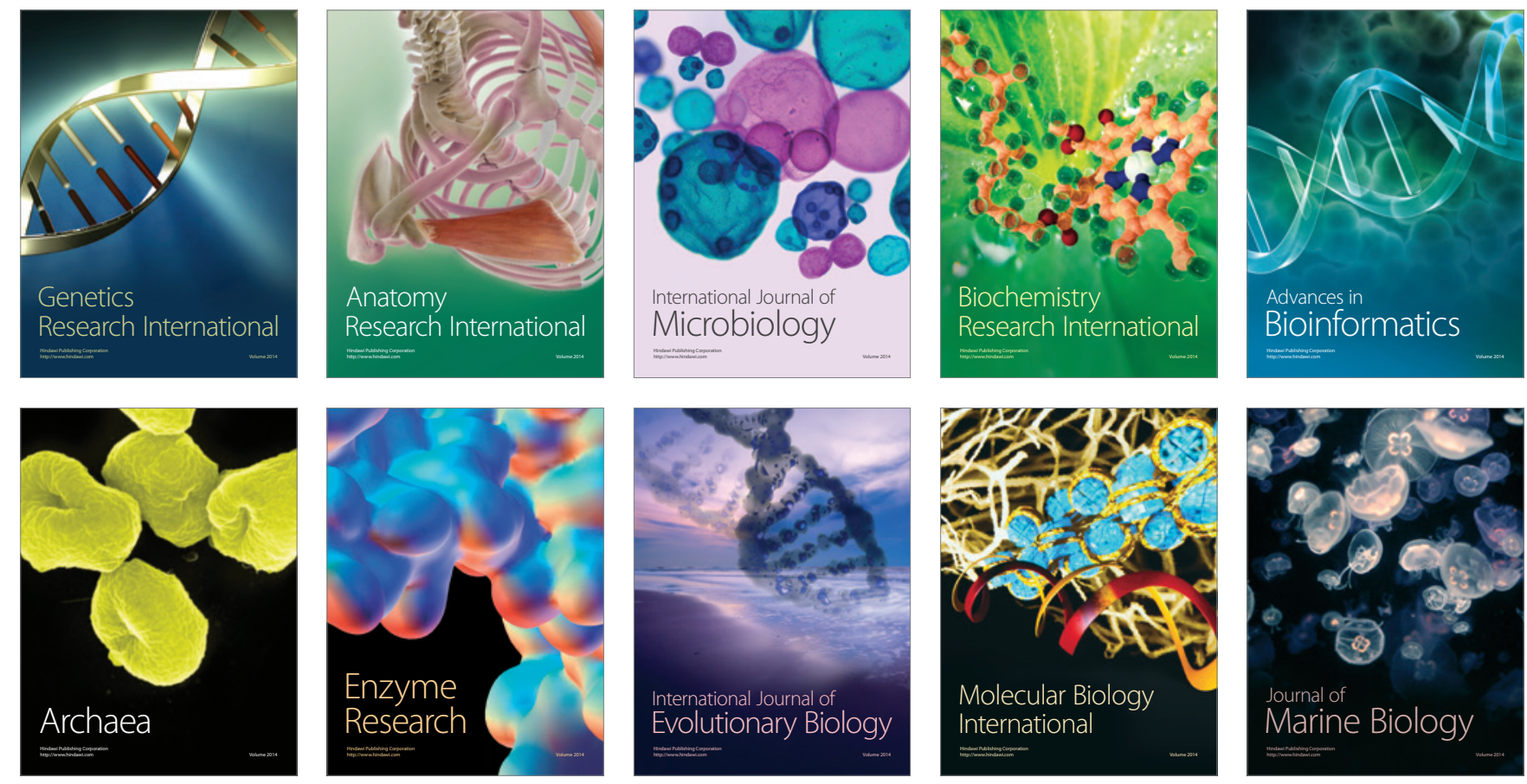